\title{
The first tracheal injury reported in rugby; a case
}

\section{report}

\section{Abstract}

Introduction: Rugby is the most popular contact sport in the world outside USA1. Musculoskeletal injuries are the most common type of rugby injury. To our knowledge, a tracheal rugby injury has not previously been reported in the literature. We present the first case of tracheo-bronchial injury (TBI) reported in a rugby player

Case report: An 18-year-old male presented to the emergency department with chest pain, hemoptysis and dyspnea after a rugby injury. CT scan showed a tracheal laceration, confirmed on bronchoscopy. This was successfully repaired surgically. $\mathrm{He}$ made an uneventful recovery and was discharged after a 6-week follow-up.

Discussion: TBI has not previously been reported in rugby players and is rare in sports. It is associated with significant morbidity and mortality. Early recognition, timely airway establishment and effective management of associated injuries is crucial to reduce mortality and complications.

Keywords: rugby, broncoscopy, haemoptysis, tracheobronchial injury, airway management, mediastinal emphysema
Volume 8 Issue I - 2018

\author{
Nik Mbakada,' Darren Yap, ${ }^{2}$ Adil Hasnain,' \\ Ipshita Banerjeer' \\ 'Emergency Department, Royal Blackburn Hospital, UK
}

'Department of Otolaryngology, Royal Berkshire Hospital, UK

\begin{abstract}
Correspondence: Nik Mbakada, Registrar in Emergency Medicine, Emergency Department, Royal Blackburn Hospital, UK, Tel 00447840563572, Fax 0I254733620,

Email nikmbakada@doctors.org.uk
\end{abstract}

Received: January 08, 2018| Published: January 22, 2018

\section{Case presentation}

A previously healthy 18 -year-old man presented to the emergency department with retrosternal chest pain, hemoptysis and dyspnea after rugby tackle. He was accidentally head butted on the sternal angle by an opponent running in the opposite direction attempting to tackle him. He immediately developed retrosternal chest pain and had to be carried off the pitch. He complained of shortness of breath with hemoptysis and was urgently transferred to hospital.

On arrival, he was alert, oriented and in moderate respiratory distress. Oxygen saturations were $88 \%$ on room air with a respiratory rate of $24 / \mathrm{min}$. This improved to $98 \%$ on high-flow $15 \mathrm{~L}$ of oxygen. The trachea was central and chest movements were symmetrical with no flail segment. Air entry was equal bilaterally and percussion was resonant on both sides. There was bruising over the sternal angle with tenderness on palpation. Heart sounds were normal on auscultation and his ECG was normal. He was hemodynamically stable.

He was kept on supplementary oxygen, started on intravenous morphine for analgesia, intravenous normal saline and kept fasted. An initial portable chest x-ray was normal as shown in Figure 1.

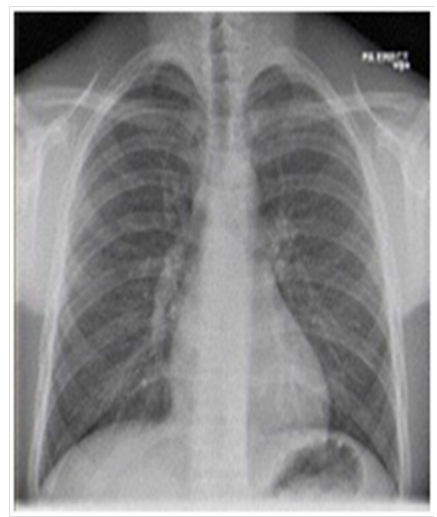

Figure I Normal chest x-ray. No evidence of the tracheal injury on the x-ray.
While still in the emergency department, he continued to have hemoptysis and developed palpable surgical emphysema at the root of the neck which raised suspicion of an ongoing air-leak from a TBI. A CT scan of the thorax was done and it showed a posterior tracheal tear $1.5 \mathrm{~cm}$ above the carina as shown in Figure 2 and bilateral lung contusions, shown in Figure 3. His dyspnea and surgical emphysema continued to worsen, so he was intubated and immediately transferred to the nearest cardiothoracic centre.

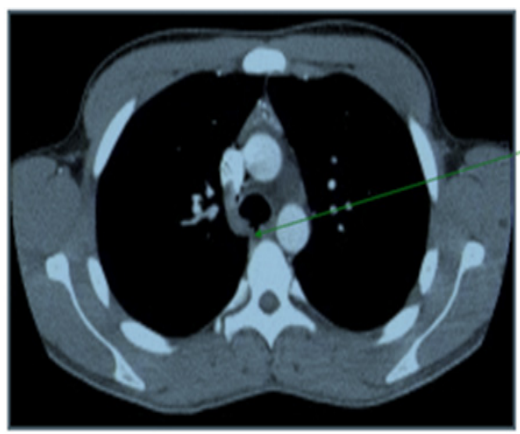

Figure 2 CT Thorax transverse view showing posterior defect in the trachea.

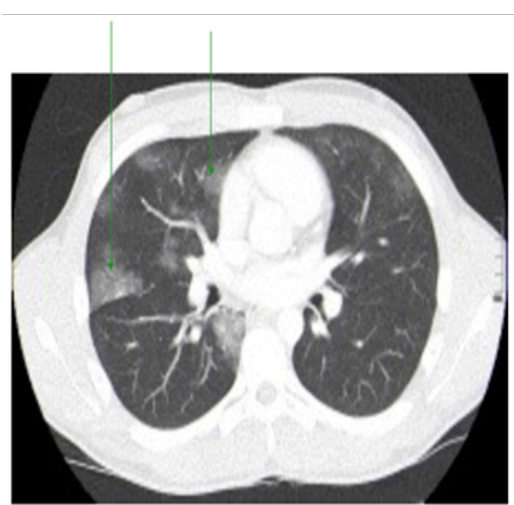

Figure 3 CT Thorax transverse view showing lung contusions. 
At the tertiary centre, emergency bronchoscopy revealed a $2.3 \mathrm{~cm}$ transverse tear of the trachea posteriorly, $1.5 \mathrm{~cm}$ above the carina which was surgically repaired. Post operatively he was kept intubated and ventilated in the intensive care unit for 2 days followed by 5 days of chest rehabilitation and physiotherapy on the respiratory ward. He received a one week course of co-amoxiclav and made an uneventful recovery. He was discharged with follow up in 6weeks.

Approximately 6 weeks after the initial presentation, the patient was well and a repeat CT thorax was normal. He was discharged without further follow up.

\section{Discussion}

Rugby is a growing sport and the Rugby World Cup is the third largest sporting event in the World, behind the FIFA World Cup and the Olympics. ${ }^{2,3}$ It is the most popular contact sport outside the USA, with frequent collisions at considerable speed between the often heavily built players. This results in thoracic injuries due to the absence of protective gear. ${ }^{4}$ The musculo-skeletal rib cage is most commonly injured, while visceral thoracic injuries are less common and are often a result of a primary rib injury. The lung is the most common internal thoracic organ to be injured in rugby. ${ }^{4}$ TBI has not previously been reported as a rugby injury. The majority of TBI are associated with complex fatal cardio-pulmonary injuries with a high pre-hospital mortality. ${ }^{5,6}$

Tracheobronchial injury (TBI) is any damage to the airway structure involving the trachea and bronchi. ${ }^{7}$ The injury can be classified in several ways as shown in Table 1 . The commonest aetiology is traumatic while the commonest mechanism is blunt trauma. ${ }^{8}$ Our patient falls into this combined group of traumatic and blunt trauma. What is unusual about our patient is that TBI due to blunt trauma usually results from high-energy impact such as falls from a height and motor vehicle accidents. The injury is rare in low-impact mechanisms. ${ }^{7}$ This raises the question of whether rugby tackles should be considered as high impact injuries equivalent to motor vehicle accidents? In physics, force is directly proportional to mass and acceleration, both of which are considerably high in rugby. For example, according to The French National Institute of Sport and Physical Education, the average weight of the rugby players at the most recent world cup in 2015 was $102.4 \mathrm{~kg}$, with the heaviest forward being the French Uini Atonio who weighed $145 \mathrm{~kg}$. The speed of some of these elite rugby players is at par with Olympic sprint athletes. At the peak of his career, one of the best known rugby players Jonah Lomu (New Zealand) weighed $120 \mathrm{~kg}$ and ran 100 metres in 10.8 seconds $(33.3 \mathrm{~km} / \mathrm{hr}, 20.7 \mathrm{miles} / \mathrm{hr}))^{9}$ The current fastest rugby players include Takudzwa Ngwenya (USA) and Bryan Habana (South Africa) who have both run $100 \mathrm{~m}$ in under 10.6 seconds, converting to an average speed of $34 \mathrm{~km} / \mathrm{hr}$ ( $21 \mathrm{miles} / \mathrm{hr})$. Albeit we could not find a clear criteria of what is considered high impact in the literature, but considering the forces involved when two rugby players weighing over $100 \mathrm{~kg}$ running at over $21 \mathrm{miles} / \mathrm{hr}$ in opposite directions collide, perhaps this should also be considered to be a high energy impact in the same class as motor vehicle accidents.

Abbreviations: TBI, trachea-bronchial injury; CT Scanm, computed tomography scan; ATLS, advanced trauma life support

TBI occur more commonly in adults than in children because children have more elastic tracheo-bronchial trees which better withstand compression forces. There is no significant difference in the incidence between men and women. ${ }^{10}$

The tracheal cartilage rings prevent longitudinal tears and their absence posteriorly makes this a more susceptible injury site. Therefore, the commonest injury pattern is transverse, and the commonest site is posteriorly and in the vicinity of the carina. ${ }^{10}$ This is exactly where the injury in our patient was found on bronchoscopy, $1.5 \mathrm{~cm}$ above the carina.

\section{Table I TBI classification}

\begin{tabular}{|c|c|}
\hline $\begin{array}{l}\text { Classification } \\
\text { criteria }\end{array}$ & Examples \\
\hline Aetiology & $\begin{array}{l}\text { I. traumatic, eg crush injury, firearm injury and } \\
\text { sharp instrument injury } \\
\text { 2. iatrogenic, eg intubation, bronchoscopy } \\
\text { 3. inhalation eg smoke } \\
\text { 4. aspiration eg foreign body }\end{array}$ \\
\hline $\begin{array}{l}\text { Mechanism of } \\
\text { injury }\end{array}$ & $\begin{array}{l}\text { I. blunt, e.g. blunt trauma to neck or chest from } \\
\text { traffic accidents. } \\
\text { 2. penetrating, eg penetrating trauma from gun } \\
\text { shots, iatrogenic }\end{array}$ \\
\hline $\begin{array}{l}\text { Anatomic site of } \\
\text { injury }\end{array}$ & $\begin{array}{l}\text { I. cervical tracheal injury } \\
\text { 2. thoracic tracheal injury } \\
\text { 3. major bronchial injury } \\
\text { 4. lobar/segmental bronchial injury. }\end{array}$ \\
\hline $\begin{array}{l}\text { Time of } \\
\text { presentation }\end{array}$ & $\begin{array}{l}\text { I. acute e.g. less than } 48 \mathrm{hrs} \text { post injury } \\
\text { 2. delayed e.g. more than } 48 \mathrm{hrs} \text { post injury }\end{array}$ \\
\hline $\begin{array}{l}\text { Anatomical } \\
\text { pattern of injury }\end{array}$ & $\begin{array}{l}\text { I. transverse e.g. in between the tracheal } \\
\text { cartilage rings } \\
\text { 2. longitudinal e.g. across the tracheal cartilage } \\
\text { rings } \\
\text { 3. spiral eg in between and across the cartilage } \\
\text { rings. }\end{array}$ \\
\hline $\begin{array}{l}\text { Extent of } \\
\text { thickness damage }\end{array}$ & $\begin{array}{l}\text { I. complete e.g. all layers of tissue surrounding } \\
\text { the airway are damaged. } \\
\text { 2. incomplete e.g. layer of tissue surrounding the } \\
\text { airway remains intact and can keep the air in } \\
\text { the airway }\end{array}$ \\
\hline
\end{tabular}

The high pre-hospital mortality rate for TBI makes it difficult to get accurate mortality statistics. Those who make it to hospital have an estimated mortality of $9 \% .{ }^{11}$ The number of people reaching hospital alive has increased due to modern advances in prehospital care. Of those who reach the hospital alive but then die, most do so due to acute complications within the first two hours of arrival. ${ }^{12}$ Prompt diagnosis and immediate management is therefore imperative. Our patient was investigated, managed and stabilised for tertiary transfer within one and a half hours of arrival to hospital.

Signs and symptoms vary depending on the severity, anatomical site and pattern of injury. Hemoptysis and shortness of breath are the commonest presentations. Dyspnea is found in $76-100 \%$ and hemoptysis in up to $25 \%$ of the cases. ${ }^{8}$ Our patient presented with both of these symptoms. Other features are dependent on associated injuries and include stridor and dysphonia in cervical tracheal injuries. Shock is more common in those with cardio-vascular injuries. The commonest injury associated with TBI is at least one rib fracture. ${ }^{8}$ Our patient did not have rib fractures, but had lung contusions. This shows that TBI can still occur without the commonly associated rib cage injuries.

Plain chest $\mathrm{x}$-ray is a valuable initial investigation as it is cheap, often readily available, fast and portable. ${ }^{13}$ It can often diagnose 
associated injuries such as tracheal defects, pneumomediastinum, surgical emphysema, rib fractures, hemothorax and pneumothorax. CT Scan is valuable in trauma because it identifies airway and associated injuries such as mediastinal injuries more accurately than $\mathrm{x}$-rays. However, due to the technical requirements and the time it takes to complete, CT scan is contra-indicated in unstable patients. Bronchoscopy is the gold standard to evaluate TBI because it provides a real time visual assessment of the location and extent of the injury, while simultaneously facilitating repair. It can be applied easily and quickly even in the presence of accompanying injuries such as $\mathrm{C}$-spine fractures. During bronchoscopy of intubated patients, the tube must be carefully retracted in order not to overlook proximal tracheal injuries. ${ }^{14}$ All patients with hemoptysis and suspected TBI should be considered for bronchoscopy.

The clinical management of TBI can be broadly divided into the immediate and the definitive care. The priority of the immediate care is to establish a secure airway; the first step in trauma management as per ATLS guidelines. An unstable patient with suspected airway injury should be intubated, preferably under flexible bronchoscopy guidance. Stable patients can be observed closely with monitoring and provision to intubate should they deteriorate. In our patient, intubation was delayed because the patient was initially stable on supplementary oxygen, however, a decision was latter made to intubate him due to progressing dyspnea, surgical emphysema and to facilitate safe interhospital transfer.

Definitive management can be divided into surgical or nonsurgical. The management will be based on a combination of factors such as the location, severity of injury and stability of the patient. ${ }^{7}$ Small injuries less than $1.5 \mathrm{~cm}$ without other associated injuries in stable patients can be managed non-surgically. In almost all penetrating injuries, surgical repair is considered a standard. ${ }^{15}$ Surgery is also indicated if the injury compromises ventilation, mediastintis, persistent pneumothorax progressive subcutaneous and mediastinal emphysema. ${ }^{16}$ Other indications for surgery are a tear more than a third of the airway circumference and in patients who need positive pressure ventilation. ${ }^{17}$

Early diagnosis and prompt intervention minimises complications. Those who die soon after the injury often suffer early compromise of vital functions due to pneumothorax, hemothorax, inadequate airway and bleeding. Late complications include mediastinitis, pneumonia, sepsis, multi-organ failure and airway strictures. ${ }^{17}$

Strict rules for players to make contact safely, health and safety promotion and use of protective gear will help to prevent TBI in rugby.

\section{Learning points}

i. Those involved in the care of sports injuries should be vigilant and weary that serious visceral injuries such as TBI can occur in rugby even in the absence of rib fractures. X-rays may be normal. Those involved in the sport should recognise TBI symptoms early and seek medical attention promptly.

ii. Serious internal injuries can occur in rugby due to unprotected high impact between players.

iii. As the sport grows, the average weight and speed of the players is increasing and more likely to produce more unusual injuries often associated with high speed. Physicians should therefore adopt a vigilant approach and be aware that they may encounter an increased frequency of such rare severe injuries as the sport continues to grow. iv. Symptomatic thoracic injuries need to be fully characterised by cross sectional imaging even in the presence of normal plain $\mathrm{x}$-rays. All patients with hemoptysis and suspected TBI after trauma should be considered for bronchoscopy.

v. TBI may be present in isolation in the absence of rib or other thoracic injuries.

vi. High impact sports such as rugby should consider incorporating gear to protect the torso. Those involved in the sport should have appropriate health and safety education, be able to recognise serious symptoms and seek medical attention appropriately.

\section{Acknowledgements}

None.

\section{Conflict of interest}

The author declares no conflict of interest.

\section{References}

1. Cuellar TA, Lottenberg L, Moore FA. World J Blunt cerebrovascular injury in rugby and other contact sports: case report and review of the literature. World J Emerg Surg. 2014;9(36).

2. Rugby World Cup 2015 Official Hospitality. RWC Ltd; 2014.

3. http://www.bbc.com/sport/30326825.

4. Hayashi D, Roemer FW, Kohler R, et al. Thoracic injuries in professional rugby players: mechanisms of injury and imaging characteristics. $\mathrm{Br} \mathrm{J}$ Sports Med. 2014;48(14):1097-1101.

5. Ecker RR, Libertini RV, Rea WJ, et al. Webb Injuries of the trachea and bronchi. Ann Thorac Surg. 1971;11(4):289-298.

6. Welter S. Repair of Tracheobronchial Injuries. Thorac Surg Clin. 2014;24(1):41-50

7. Chu CP, Chen PP. Tracheobronchial injury secondary to blunt chest trauma: Diagnosis and management. Anaesthesia and Intensive Care. 2002;30(2):145-152.

8. Karmy-Jones R, Wood ED. Traumatic injury to the trachea and bronchus. Thorac Surg Clin. 2007;17(1):35-46.

9. Irish Examiner. Tribute to Jonah Lomu strikes a chord around the world. irishexaminer. com. Retrieved 21 November 2015.

10. Bertelsen S, Howitz P. Injuries of the trachea and bronchi Thorax. Bmj.1972;27:188.

11. Kiser AC, Brien SM, Detterbeck FC. Blunt tracheobronchial injuries: treatment and outcome. Annals of Thoracic Surgery. 2001;71(6):20592065.

12. Nakayama DK, Rowe MI. Intrathoracic tracheobronchial injuries in childhood. International Anesthesiology Clinics. 1988;26(1):42-49.

13. Euathrongchit J, Thoongsuwan N, EJ Stern. Nonvascular mediastinal trauma. Radiologic Clinics of North America. 2006;44(2):251-58.

14. Altinok T, Can A. Management of Tracheobronchial Injuries. Eurasian $J$ Med. 2014;46(3):209-215.

15. Mussi A, Ambrogi MC, Ribechini A. Acute major airway injuries: clinical features and management. European Journal of Cardio-Thoracic Surgery. 2001;20(1):46-52.

16. Johnson (SB) Tracheobronchial injury. Seminars in Thoracic and Cardiovascular Surgery. 2008;20(1):52-57.

17. Atkins BZ, Abbate S, Fisher SR, et al. Current management of laryngotracheal trauma:Case report and literature review. J Trauma. 2004;56(1):185-190 